\title{
Mechanical Properties of Steel-FRP Composite Bars under Tensile and Compressive Loading
}

\author{
Zeyang Sun, ${ }^{1}$ Yu Tang, ${ }^{2}$ Yunbiao Luo, ${ }^{3}$ Gang Wu, ${ }^{1,2}$ and Xiaoyuan $\mathrm{He}^{2}$ \\ ${ }^{1}$ Southeast University, Key Laboratory of Concrete and Prestressed Concrete Structures of the Ministry of Education, \\ Nanjing 210096, China \\ ${ }^{2}$ School of Civil Engineering, Southeast University, Nanjing 210096, China \\ ${ }^{3}$ Department of Civil Engineering, Tianjin University, Tianjin 300072, China
}

Correspondence should be addressed to Gang Wu; g.wu@seu.edu.cn

Received 20 October 2016; Accepted 4 December 2016; Published 3 January 2017

Academic Editor: Jun Deng

Copyright (C) 2017 Zeyang Sun et al. This is an open access article distributed under the Creative Commons Attribution License, which permits unrestricted use, distribution, and reproduction in any medium, provided the original work is properly cited.

\begin{abstract}
The factory-produced steel-fiber reinforced polymer composite bar (SFCB) is a new kind of reinforcement for concrete structures. The manufacturing technology of SFCB is presented based on a large number of handmade specimens. The calculated stress-strain curves of ordinary steel bar and SFCB under repeated tensile loading agree well with the corresponding experimental results. The energy-dissipation capacity and residual strain of both steel bar and SFCB were analyzed. Based on the good simulation results of ordinary steel bar and FRP bar under compressive loading, the compressive behavior of SFCB under monotonic loading was studied using the principle of equivalent flexural rigidity. There are three failure modes of SFCB under compressive loading: elastic buckling, postyield buckling, and no buckling (ultimate compressive strength is reached). The increase in the postyield stiffness of SFCB $\left(r_{\text {sf }}\right)$ can delay the postyield buckling of SFCB with a large length-to-diameter ratio, and an empirical equation for the relationship between the postbuckling stress and $r_{\text {sf }}$ is suggested, which can be used for the design of concrete structures reinforced by SFCB to consider the effect of reinforcement buckling.
\end{abstract}

\section{Introduction}

Fiber Reinforced Composites (FRP) have been widely used in the aerospace, shipbuilding, automobile, and mechanical industries since the 1940s. In recent years, FRP has become a new type of reinforcement for civil engineering with high strength, light weight, and anticorrosion performance $[1$, 2]. The design guidelines for the FRP bar for prestressing concrete structures were proposed by an ACI committee [3]. With the development of research and application, the shortcomings of different types of FRP include the following: (1) the ultimate tensile strain of FRP is generally not more than $3 \%$, which cannot meet the ductility demand for concrete structures located in a region of high seismic hazard; (2) the price of carbon FRP (CFRP) cannot meet the lowcost requirements for use in civil engineering; (3) the shear strength of FRP is approximately $5 \%$ of its tensile strength, and the brittle FRP may be broken during the construction process (concrete vibration, anchoring, or bending); (4) the elastic modulus of glass FRP (GFRP) or basalt FRP (BFRP) is low, which cannot guarantee the stiffness of the corresponding concrete structures. Studies on concrete beams reinforced by hybrid FRP were conducted to enhance the stiffness or ductility [4]; however, the ductility was achieved as a result of the partial fracture of fibers with low elongation rates. Steel bar has the characteristics of low strength, high elastic modulus, high ductility, poor durability, and large density, while FRP has the opposite characteristics. By combining steel and FRP, a composite bar with optimized performance can be obtained, and the hybrid reinforced concrete beams were studied by research from the perspective of corrosion control and improvement in stiffness $[5,6]$.

As shown in Figure 1, the stable postyield stiffness $\left(E_{2}\right)$ of a steel-FRP composite bar (SFCB) [7] can be achieved by combining the linear elastic FRP and the elastic-plastic steel bar. Compared with steel bars, the weight of SFCB is comparatively reduced, and the anticorrosion performance is enhanced. Compared with a pure FRP bar, the stiffness of 

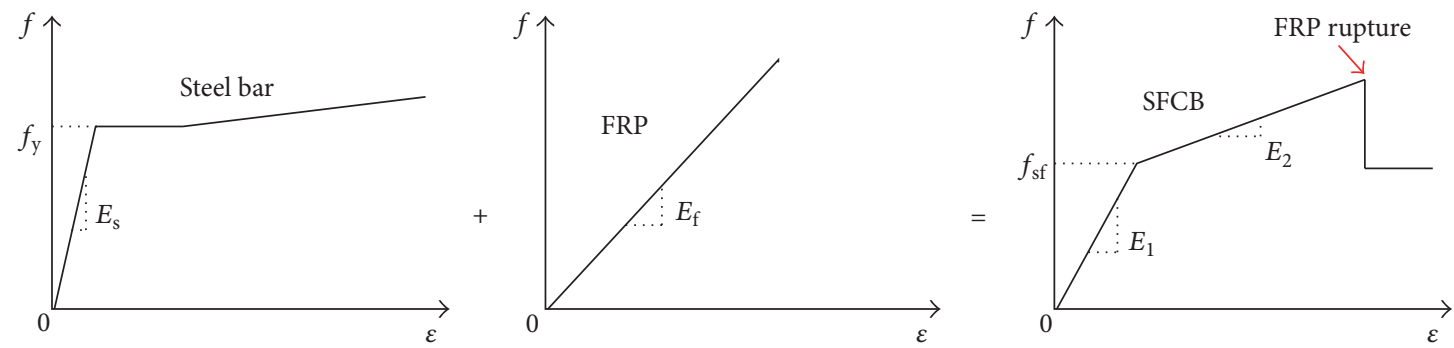

FIGURE 1: Schematic view of the mechanical property of an SFCB.

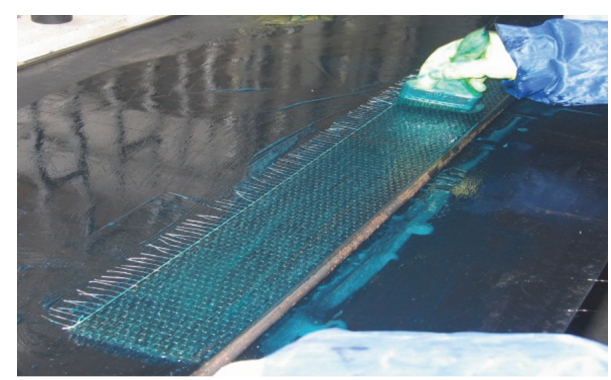

(a) Resin brushing

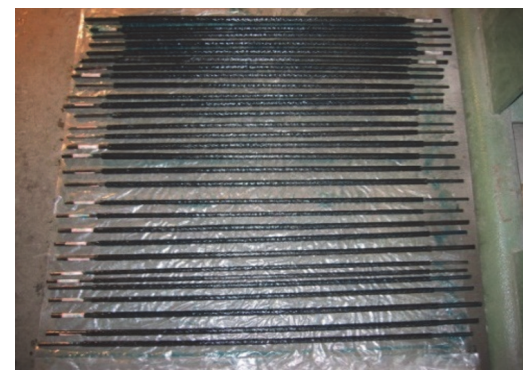

(b) Handmade SFCB specimens

FIGURE 2: Exploratory handmade SFCB specimens.

the composite bar is greatly improved, especially for a GFRP or BFRP bar [8], and the cost is much lower. Compared to a GFRP bar, a BFRP bar can have a relatively higher stiffness and strength with the same cost [9], and the fatigue behavior and the degradation mechanism of BFRP under different stress levels of cyclic loadings were conducted [10] by Zhao et al. in Southeast University. BFRP was adopted to produce the composite bar (steel-BFRP composite bar) in this study.

The mechanical behavior of SFCB [11], the static behavior of concrete beams reinforced by SFCB [12], and concrete beams strengthened by near-surface-mounted (NSM) SFCB [13] were conducted by our research group. These studies demonstrated that the effective postyield stiffness of SFCB can improve the corresponding reinforced concrete structures. To improve the seismic performance of concrete structures, SFCB can be used as the longitudinal reinforcement to form a controllable postyield stiffness [14, 15]. In addition, the bond strength between SFCB and concrete can be optimized to enhance the seismic performance of the structure [16]. This paper mainly introduces the technology of factory-produced SFCB and its mechanical properties under tensile/repeated tensile loading. Based on the experimental results for ordinary steel bars and FRP bar under compressive loading, the effects of postyield stiffness and equivalent length-todiameter ratio (ELDR) of the SFCB on compressive behavior were analyzed.

\section{Factory Production of SFCB}

SFCB has several key interfaces that include the fiber/resin matrix, steel/FRP, and SFCB/environmental media. The shear performance of the interfaces directly reflects the mechanical property of SFCB. The debonding of FRP at the interface between the fiber and resin matrix can effectively adjust the stress distribution inside the FRP, and the ultimate strength of fiber can be fully utilized. The key production technology and the basic mechanical properties of the SFCB were carried out based on numerous exploratory trials (Figure 2) using parameters including inner steel type (round or ribbed rebar), inner steel bar diameter, FRP sheet type, steel/FRP interface treatment, and so on.

When using a round bar as the inner core, a uniform distribution of the outer longitudinal fiber can be ensured. In such a case, the strength of the FRP can be fully utilized. However, the tensile test of the corresponding SFCB shows that the relative slip between the round inner steel bar and outer FRP happened. The anchorage test demonstrated that the bonding performance between round steel bar and the outer FRP was difficult to guarantee. As a result, ribbed rebar with winding roving was selected as the inner core of the SFCB (Figure 3(a)). The winding roving could fill in the gaps between the ribs of the steel bar to protect the longitudinal FRP from being hurt. Meanwhile, an enhanced interface was achieved between steel bar and FRP. The factory production of SFCB was proposed by modifying the current FRP pultrusion equipment (Figure 3(b)), and the surface rib was formed by winding a plastic tape with a specific width during the pultrusion process. The modified pultrusion equipment can also be used to produce steel wire-FRP composite bar or steel-hybrid FRP composite bar for different structural needs. 


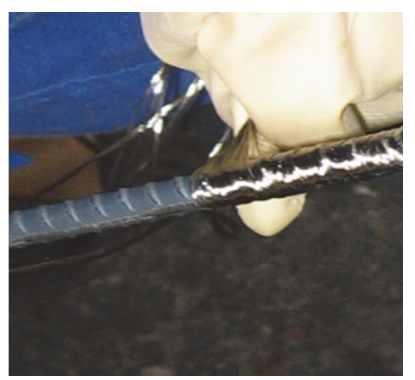

(a) Ribbed rebar with winding roving

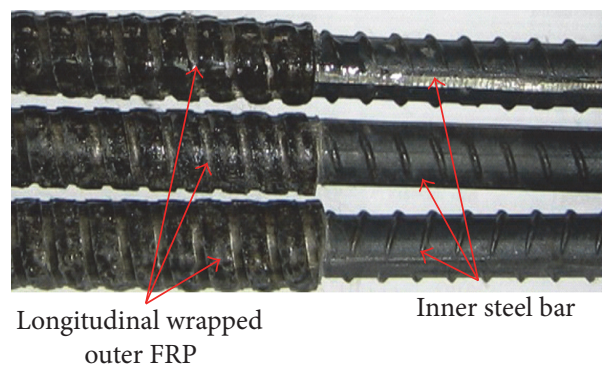

(b) Factory-produced SFCB

FIgURE 3: Factory-produced SFCB and its interface treatment.

TABLE 1: Mechanical properties of steel bar, basalt fibers, and SFCBs.

\begin{tabular}{lcccc}
\hline Material type & $\begin{array}{c}\text { Elastic modulus } \\
\text { GPa }\end{array}$ & $\begin{array}{c}\text { Yield strength } \\
\text { MPa }\end{array}$ & $\begin{array}{c}\text { Ultimate strength } \\
\text { MPa }\end{array}$ & $\begin{array}{c}\text { Elongation rate } \\
(\%)\end{array}$ \\
\hline Steel bar (HRB400) & 200 & 420 & 580 & 15 \\
S10-B20 & 140.03 & 309.6 & 541.8 & 2.5 \\
S10-B30 & 138.10 & 302.35 & 573.45 & 2.3 \\
20 bundles of basalt fiber & 60 & - & 1670 & 2.5 \\
30 bundles of basalt fiber & 60 & - & 1500 & 2.3 \\
\hline
\end{tabular}

\section{Mechanical Properties of SFCB under Tensile and Repeated Tensile Loading}

The mechanical properties of SFCB can be expressed based on the composite law [11], and the tensile postyield stiffness ratio of SFCB $\left(r_{\text {sf }}\right)$ can be calculated by

$$
r_{\mathrm{sf}}=\frac{E_{\mathrm{f}} A_{\mathrm{f}}}{\left(E_{\mathrm{s}} A_{\mathrm{s}}+E_{\mathrm{f}} A_{\mathrm{f}}\right)},
$$

where $E_{\mathrm{f}}$ and $A_{\mathrm{f}}$ are the elastic modulus and cross-sectional area of the outer FRP of the SFCB, respectively, and $E_{\mathrm{s}}$ and $A_{\mathrm{s}}$ are the elastic modulus and cross-sectional area of the inner steel bar, respectively.

The mechanical properties of the steel bar, basalt fiber, and SFCBs obtained experimentally are shown in Table 1, in which S10-B20 represents the SFCB made of $10 \mathrm{~mm}$ diameter inner steel bar longitudinally wrapped by 20 bundles of 2400 tex basalt fiber. The unit "tex" represents the weight in grams of each bundle fiber 1000 meters long. It can be seen from Table 1 that the strength of the basalt fiber with 20 bundles in S10-B20 was approximately $65.7 \%$ of the original fiber strength. Moreover, the effective strength of the basalt fiber will be further decreased by the increasing amount of basalt fiber. For example, the average strength of 30 bundles of basalt fiber in S10-B30 was approximately $57.3 \%$ of the original fiber. The reason for this strength reduction could be due to the fact of the inevitable nonuniformity of the outer fiber during the SFCB pultrusion process, which would result in an initial bending and partial fracture of the outer fiber.
The numerical models for the inner steel bar and the outer FRP of the SFCB were separately established in OpenSees ([17]), and ReinforcingSteel was adopted for the steel bar by defining the yield point $\left(f_{\mathrm{y}}, \varepsilon_{\mathrm{y}}\right)$, hardening point $\left(f_{\mathrm{sh}}, \varepsilon_{\mathrm{sh}}\right)$, tangent at initial strain hardening $\left(E_{2}\right)$, and the peak stressstrain point $\left(f_{\mathrm{u}}, \varepsilon_{\mathrm{u}}\right)$. The mechanical behavior of FRP in SFCB was set according to the test results; the interface of steel/FRP was assumed to be perfect bonding. The load-strain curves of inner steel bar and S10-B20 under repeated tensile loading are presented in Figure 4. It can be found that the calculated values were basically in agreement with the experimental curves. Compared with an ordinary steel bar, an SFCB can achieve less residual strain under the same unloading strain and therefore reduce the unloading residual strain of an SFCB reinforced concrete structure. There are two reasons for this advantage: (1) the unloading stress level of an SFCB is higher than an ordinary steel bar with the same unloading strain and unloading stiffness; (2) when the inner steel bar of an SFCB reaches " 0 " stress with the plastic residual strain, the corresponding FRP still remains in "tension" due to the residual tensile strain of inner steel bar. Therefore, the FRP will further compress the inner steel bar and then decrease the residual strain of the SFCB. After S10-B20 reached a relatively large strain $(>13500 \mu \varepsilon)$, the tested residual strain was slightly larger than the calculated value, which indicated that the compression effect of the linear elastic FRP on the inner steel bar was reduced.

The energy-dissipation capacity of a steel bar and an SFCB that achieve the same unloading strain was shown in Figure 5(a), which can be calculated by the integration of the 


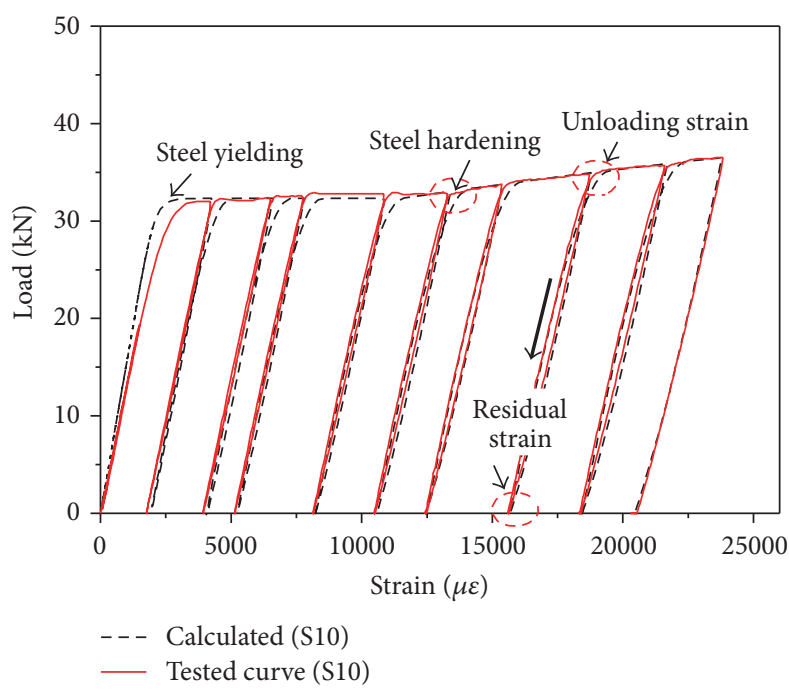

(a) Steel bar $(10 \mathrm{~mm})$

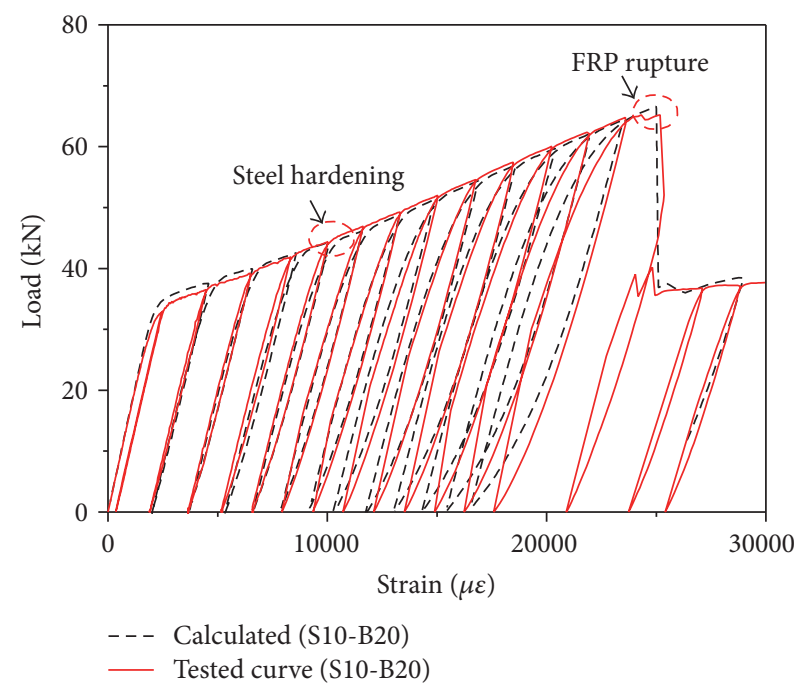

(b) SFCB (S10-B20)

FIGURE 4: Typical performance of a steel bar and an SFCB under repeated tensile loading.

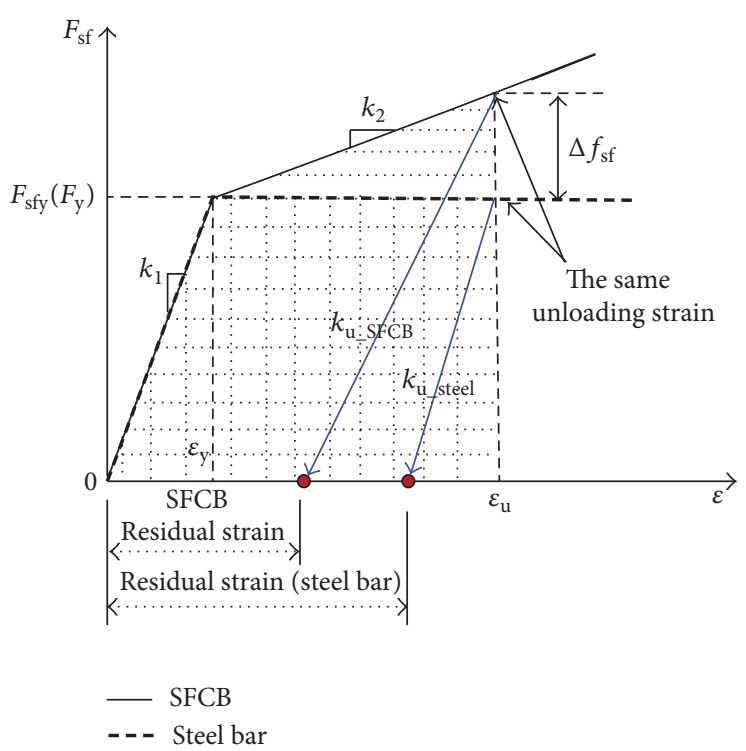

(a) Comparison of energy dissipation between SFCB and steel bar

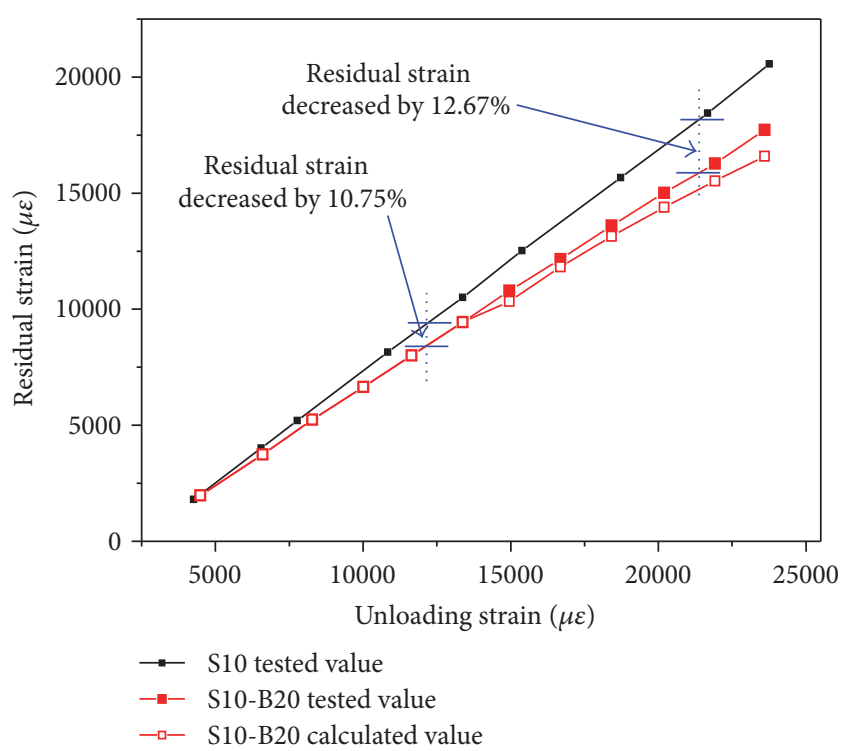

(b) Residual strain of SFCB and steel bar

FIGURE 5: Energy-dissipation capacity and residual strain of SFCB and steel bar.

load-strain curve. The hardening of the steel bar is very small before the FRP fractures; therefore, the ratio of the dissipated energy of the inner steel bar $\left(S_{\text {steel }}\right)$ to the SFCB $\left(S_{\mathrm{SFCB}}\right)$ can be calculated as follows:

$$
\frac{S_{\mathrm{SFCB}}}{S_{\text {steel }}}=\frac{r_{\mathrm{sf}}\left(\varepsilon_{\mathrm{u}}-\varepsilon_{\mathrm{y}}\right)^{2}}{2 \varepsilon_{\mathrm{y}} \varepsilon_{\mathrm{u}}-\varepsilon_{\mathrm{y}}{ }^{2}},
$$

where $\varepsilon_{\mathrm{y}}$ and $\varepsilon_{\mathrm{u}}$ are the yield strain and ultimate strain, respectively. It can be seen that with the increase of $r_{\text {sf }}$ the SFCB has a larger energy-dissipation capacity at the same peak strain.
The experimental and calculated residual strains of S10B20 are shown in Figure 5(b). Only the experimental values of the steel bar (S10) were listed because the calculated values were basically consistent with the experimental values. It can be found that the residual strain of S10-B20 was reduced by approximately $10 \%$ compared with the corresponding steel bar, and the reduction of the residual strain slightly increased when the strain approached the ultimate stage (Figure 5(b)). The tested residual strain of S10-B20 was slightly larger than that of the calculated value. The reasons for this are mainly as follows: (1) FRP is assumed to be completely straight in the calculation and the steel bar had no initial bending, while in the experiment the surface of the SFCB was formed by 


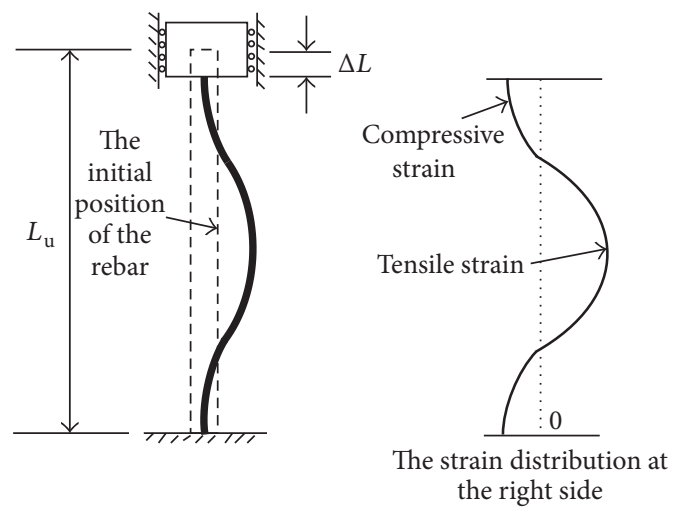

(a) Schematic view of rebar under compression

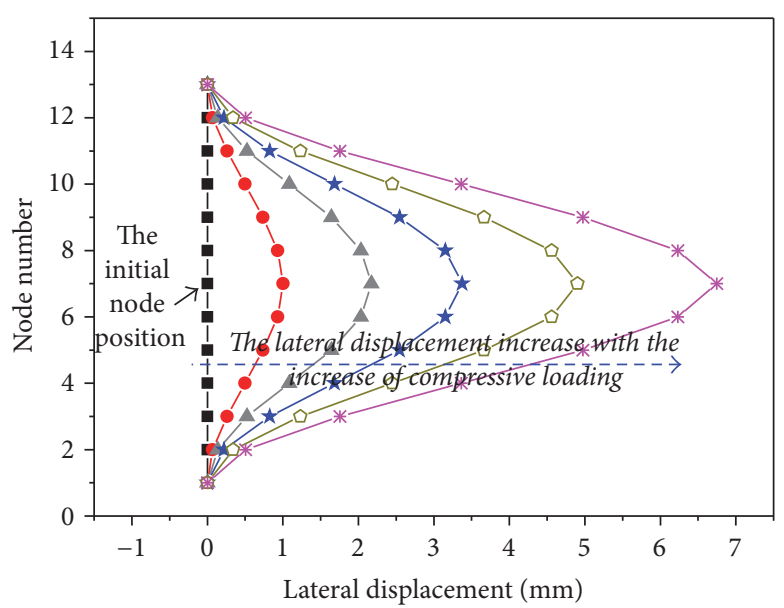

(b) Residual strain of SFCB and steel bar

Figure 6: The mechanics of a steel bar under compressive loading.

a plastic band; that is, the longitudinal fibers were partially curved, resulting in an FRP strain slightly behind that of the inner steel bar; (2) the inner steel bar was assumed to work together with the outer FRP, while in reality a relative slip occurred at the steel/FRP interface after the inner steel bar yielded.

\section{The Compressive Behavior of SFCB}

4.1. The Compressive Behavior of Ordinary Steel Bar. When partial spalling of the concrete cover of a concrete column occurs, the longitudinal rebar would be exposed to the environment with the stirrup [18], and the mechanical model in the laboratory can be regarded as having both ends fixed (Figure 6(a)). With the development of the compression force, the left side of the middle part was in compression while the right side was in tension. The lateral deformation of the middle section increased with the development of compressive loading (Figure 6(b)).

A great amount of experimental and theoretical research on the compressive behavior of steel bars has been conducted [19-21]. The main parameters were the geometric shape of the rebar, yield strength (ordinary steel bar, high-strength steel bar), hardening degree, and loading pattern (unidirectional compression, cyclic tensile, and compressive loading). The ratio between the tested length and diameter of the steel bar $\left(r_{L D}\right)$ was defined as follows:

$$
r_{L D}=\frac{L_{\mathrm{u}}}{d_{\mathrm{b}}}
$$

where $L_{\mathrm{u}}$ and $d_{\mathrm{b}}$ are the calculated length of longitudinal reinforcement and rebar diameter, respectively.

An experimental study on the hysteretic behavior of the steel bars subjected to tensile, repeated tensile and cyclic tensile, and compressive loading was conducted by Zheng [22]. The comparison between the test results and the corresponding calculated curves is shown in Figure 7, in which the elastic modulus of the rebar was $E_{\mathrm{s}}=200 \mathrm{GPa}$, yield strength $f_{\mathrm{y}}=568 \mathrm{MPa}$, hardening strain $\varepsilon_{\mathrm{sh}}=0.1505$, and ultimate strength $f_{\mathrm{u}}=1.286 f_{\mathrm{y}}$. It is found that the tensile skeleton curve agrees well with the experimental results (Figure $7(\mathrm{a})$ ). Figures 7 (b) -7 (d) illustrated the simulation results of the compressive behavior of the rebar with $r_{L D}$ of 10 and 20 . The initial lateral drift of the middle node was set to be $1 / 1000$ of the diameter to achieve a uniform buckling mode. It was found that the calculated backbone curves under compressive loading with $r_{L D}$ of 10 and 20 agree well with the experimental data.

The comparison of the stress-strain relationships of the steel bar under cyclic loading $\left(r_{L D}=20\right)$ is presented in Figure $7(\mathrm{~d})$. The calculated curve cannot exactly agree with the tested result due to the convergence problem. To avoid the influence of the effect of the loading path on the compressive behavior of SFCB, the performance of SFCB under monotonous compressive loading is presented.

4.2. The Compressive Behavior of SFCB. FRP is wrapped on the outside of the SFCB, so it is necessary to analyze the compressive behavior of an FRP bar. There is a large difference between the tensile and compressive behavior of an FRP bar [23]. The difference can be caused by the fiber type, fiber volume fraction, and resin type. The failure modes of an FRP bar under compression include horizontal tensile failure, local fiber buckling, or shear failure. The compressive strength values of GFRP bar, CFRP bar, and AFRP bar are generally considered to be $55 \%, 78 \%$, and $20 \%$ of their tensile strengths, respectively [24].

The stress-strain relationship of SFCB under compressive loading (see (4)) can be obtained according to the constitutive relation under tensile loading [7]:

$$
\begin{aligned}
& f_{\mathrm{sf}}^{-} \\
& = \begin{cases}\frac{\varepsilon_{\mathrm{sf}}{ }^{-}\left(E_{\mathrm{s}} A_{\mathrm{s}}+E_{\mathrm{f}}{ }^{-} A_{\mathrm{f}}\right)}{A}, & 0<\left|\varepsilon_{\mathrm{sf}}{ }^{-}\right| \leq\left|\varepsilon_{\mathrm{sfy}}{ }^{-}\right| \\
f_{\mathrm{sfy}}{ }^{-}+\frac{\left(\varepsilon_{\mathrm{sf}}{ }^{-}-\varepsilon_{\mathrm{sfy}}{ }^{-}\right) E_{\mathrm{f}}{ }^{-} A_{\mathrm{f}}}{A}, & \left|\varepsilon_{\mathrm{sfy}}{ }^{-}\right|<\left|\varepsilon_{\mathrm{sf}}{ }^{-}\right| \leq\left|\varepsilon_{\mathrm{sfu}}{ }^{-}\right| \\
\frac{f_{\mathrm{y}}{ }^{-} A_{\mathrm{s}}}{A}, & \left|\varepsilon_{\mathrm{sfu}}{ }^{-}\right|<\left|\varepsilon_{\mathrm{sf}}{ }^{-}\right|,\end{cases}
\end{aligned}
$$




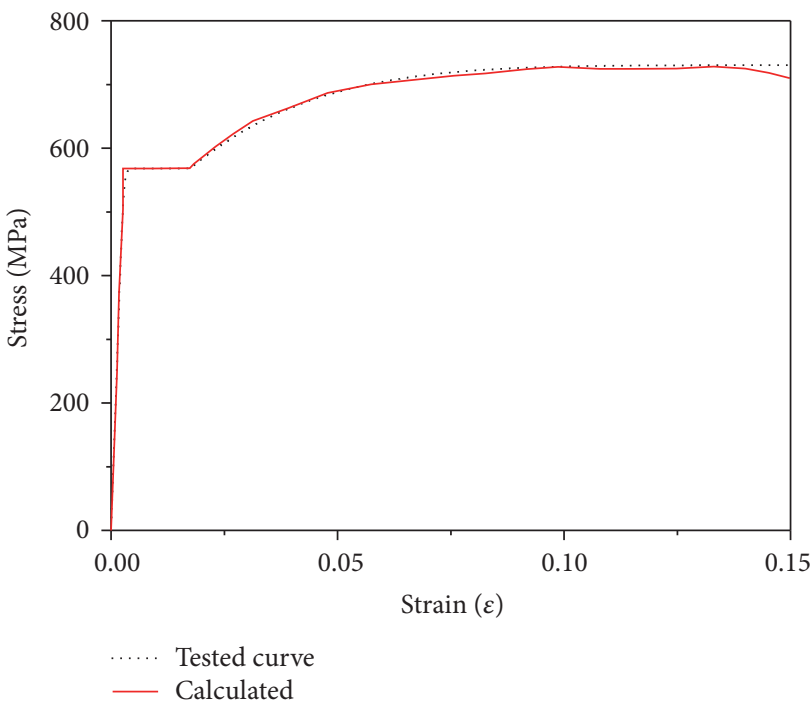

(a) Tensile behavior of the steel bar

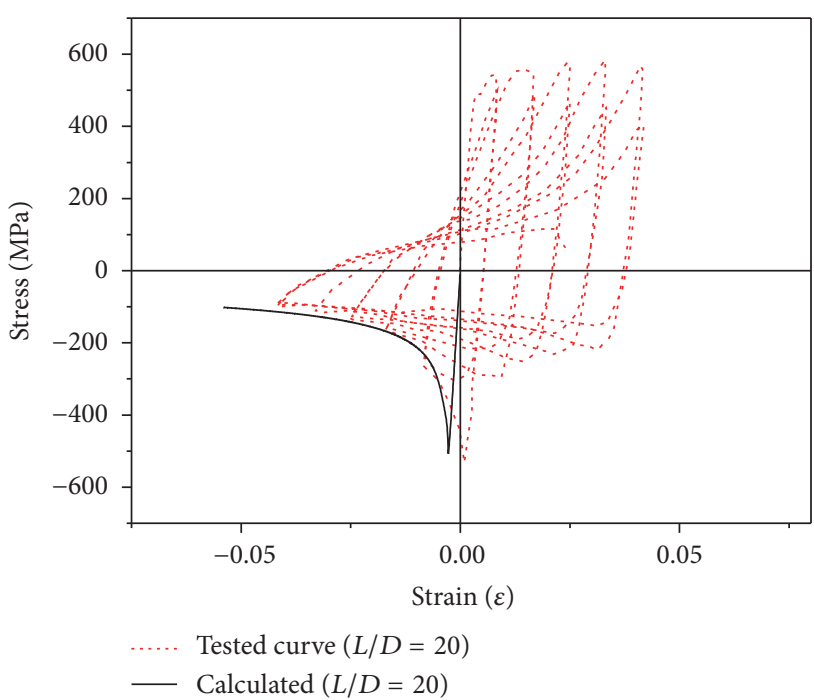

(c) $L / D=20$ (compressive loading)

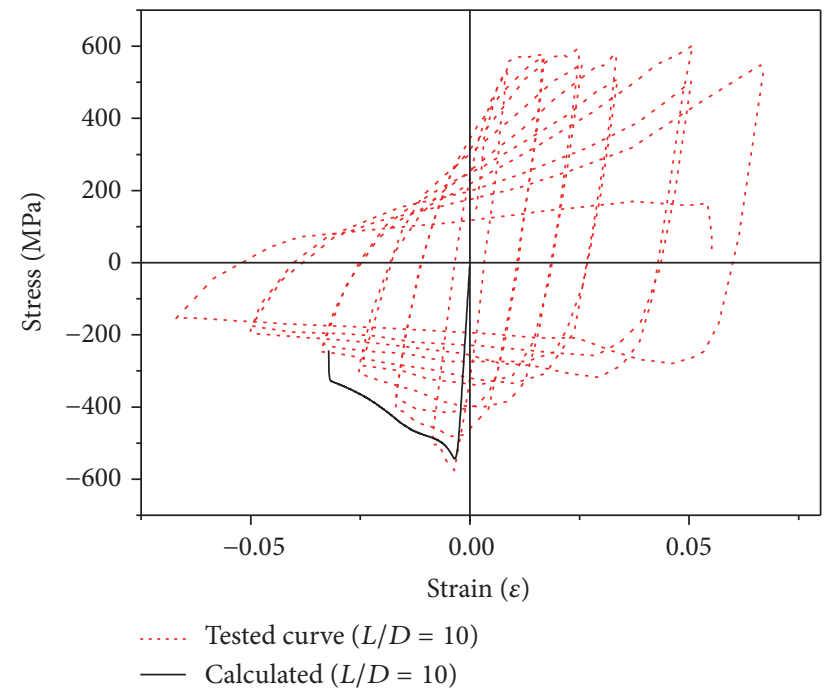

(b) $L / D=10$

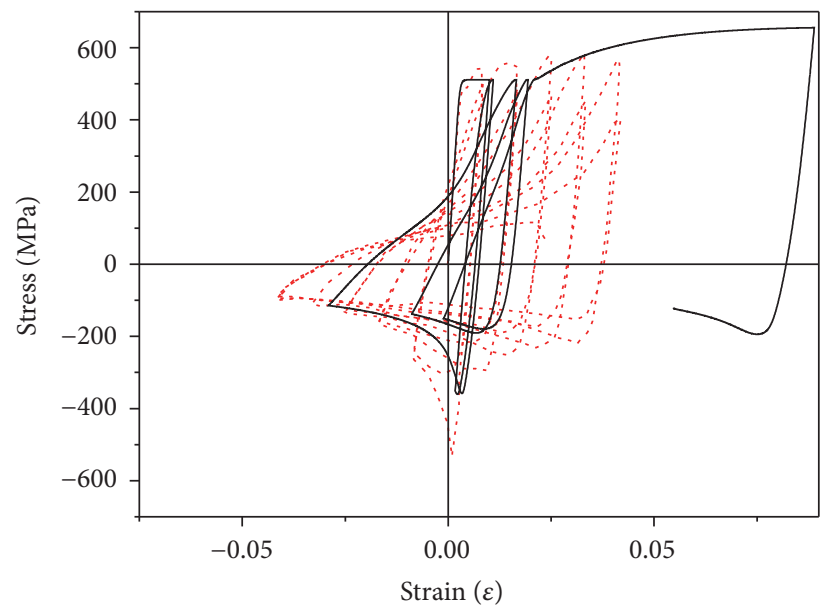

Tested curve $(L / D=20)$

Calculated $(L / D=20)$

(d) $L / D=20$ (cyclic loading)

Figure 7: Comparison of the tested and calculated results of a steel bar.

where "-" means that the SFCB is under compressive loading. The corresponding postyield stiffness ratio of SFCB under compressive loading $\left(r_{\mathrm{sf}}{ }^{-}\right)$can be calculated as follows:

$$
r_{\mathrm{sf}}^{-}=r_{\mathrm{sf}} \frac{E_{\mathrm{f}}^{-}\left(E_{\mathrm{s}} A_{\mathrm{s}}+E_{\mathrm{f}} A_{\mathrm{f}}\right)}{E_{\mathrm{f}}\left(E_{\mathrm{s}} A_{\mathrm{s}}+E_{\mathrm{f}}^{-} A_{\mathrm{f}}\right)} .
$$

It can be found that $r_{\mathrm{sf}}{ }^{-}$of an SFCB is 0 when the tensile postyield stiffness ratio $r_{\mathrm{sf}}$ is 0 , and the $r_{\mathrm{sf}}{ }^{-}$of a pure FRP bar is 1 when the corresponding $r_{\mathrm{sf}}$ is 1 .

Since there is a large difference between the compressive modulus of a steel bar and an FRP bar, the equivalent flexural rigidity of an SFCB is defined as $E_{\mathrm{s}} I_{\mathrm{sf}} \mathrm{Is}^{\mathrm{e}}=E_{\mathrm{s}} I_{\mathrm{s}}+$ $E_{\mathrm{f}} I_{\mathrm{f}}$ (Figure 8), and the corresponding equivalent diameter $\left(d_{\text {sf Is }}{ }^{\mathrm{e}}\right)$ and equivalent compressive strength $\left(f_{\text {sf.Is }}{ }^{\mathrm{e}}\right)$ of SFCB can be calculated using (6) and (7), respectively:

$$
\begin{aligned}
& d_{\text {sf_Is }}{ }^{e}=\sqrt[4]{\frac{E_{\mathrm{f}}}{E_{\mathrm{s}}}\left(d_{\mathrm{sf}}{ }^{4}-d_{\mathrm{s}}{ }^{4}\right)+d_{\mathrm{s}}^{4}}, \\
& f_{\text {sf _Is }}{ }^{\mathrm{e}}=\frac{P_{\text {sf }}{ }^{-}}{\sqrt{\left(E_{\mathrm{f}} / E_{\mathrm{s}}\right)\left(A_{\mathrm{f}}{ }^{2}+2 A_{\mathrm{s}} A_{\mathrm{f}}\right)+A_{\mathrm{s}}{ }^{2}}}
\end{aligned}
$$

where $d_{\mathrm{s}}$ and $d_{\mathrm{sf}}$ are the diameter of the inner steel bar and the diameter of the SFCB, respectively. $P_{\text {sf }}{ }^{-}$is the compressive load. The critical load $P_{\text {cr_sf }}$ of SFCB with two fixed ends can be calculated based on

$$
P_{\text {cr }- \text { ff }}=\frac{\pi^{2}\left(E_{\mathrm{s}} I_{\mathrm{s}}+E_{\mathrm{f}} I_{\mathrm{f}}\right)}{\left(\mu_{\mathrm{b}} L_{\mathrm{u}}\right)^{2}},
$$




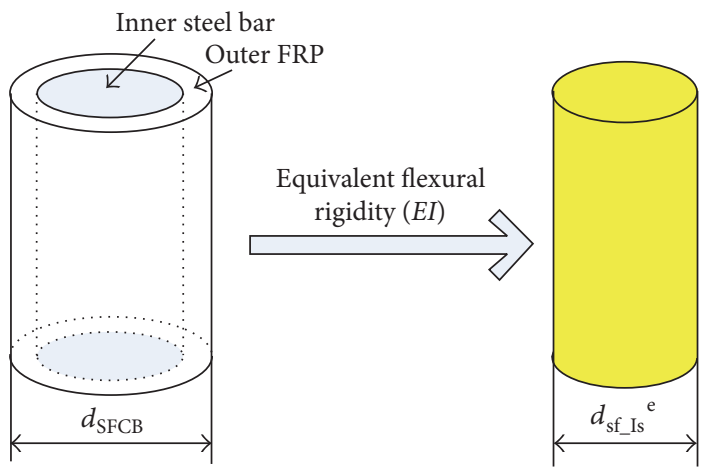

FIGURE 8: Equivalent diameter of SFCB based on equivalent flexural rigidity.

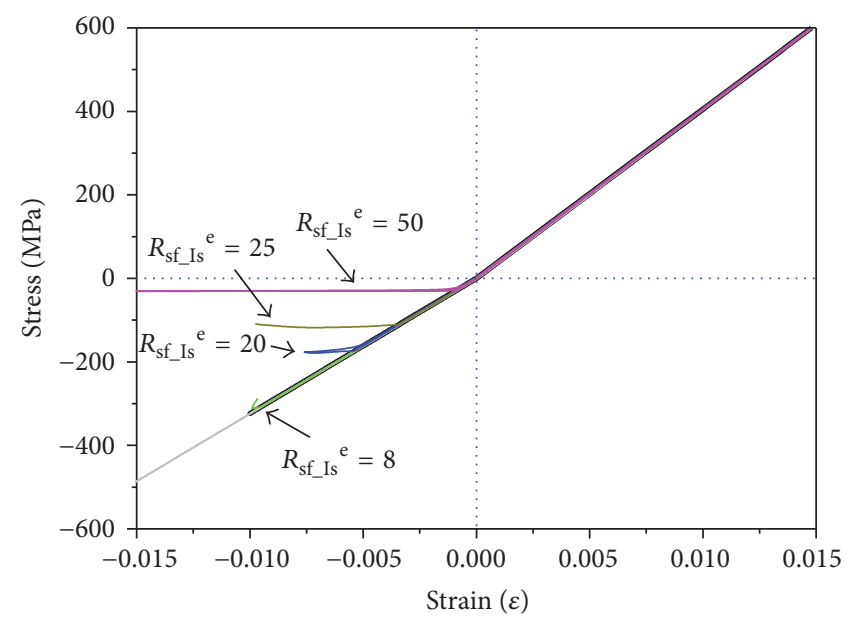

(a) BFRP bar under tensile and compressive loading

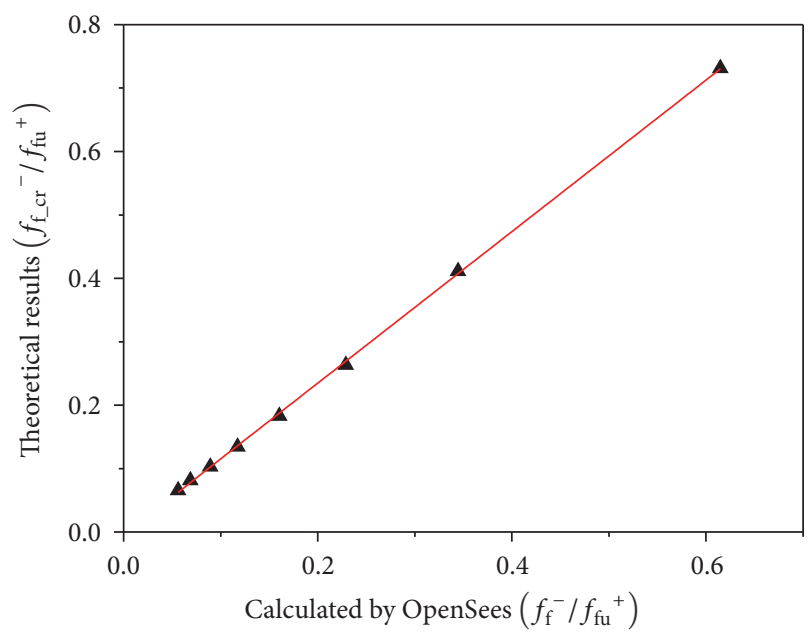

(b) The comparison between the calculated results and the theoretical results

FIGURE 9: The simulation results of a BFRP bar under cyclic loading.

where $I_{\mathrm{s}}$ and $I_{\mathrm{f}}$ are the area moments of inertia of steel bar and FRP, respectively. $\mu_{\mathrm{b}}$ is the coefficient considering the end constraints. The corresponding ELDR of SFCB is defined as $R_{\text {sf_Is }}{ }^{\mathrm{e}}=L_{\mathrm{u}} / d_{\text {sf_Is }}{ }^{\mathrm{e}}$.

4.3. Parametric Analysis of SFCB. The experimental study of the compressive behavior of BFRP bar under monotonic compressive loading has been conducted by Zhou [25], who found that the compressive elastic modulus of a BFRP bar is approximately $80 \%$ of the tensile elastic modulus, and the compressive strength is approximately $50 \%$ of the tensile strength. Based on the test results, the stress-strain behavior of the BFRP bar under tensile and compressive loading was illustrated in Figure 9(a). With an increase in $R_{\text {sf Is }}{ }^{\mathrm{e}}$, the maximum average stress of FRP bar gradually decreases due to bar buckling. The comparison between the calculated dimensionless critical compressive load and the corresponding theoretical value is presented in Figure 9(b), and the former was approximately $14.2 \%$ less than the latter, which was caused by the initial offset (1/1000 of the diameter) in the OpenSees model. The development trends of critical stress with the increase in $R_{\text {sf_Is }}{ }^{\mathrm{e}}$ are still in good agreement with each other; therefore, this calculation method can be used to analyze the compressive properties of SFCB.

The load-strain curves and equivalent stress-strain curves of SFCB, with the same $L_{\mathrm{u}} / d_{\text {sf_Is }}{ }^{\mathrm{e}}$ and different postyield stiffness ratios, are shown in Figure 10. The load-strain curve shows that the initial compressive stiffness of SFCB is kept constant (Figure 10(a)), while the initial compressive elastic modulus of SFCB decreases with the increase of $r_{\mathrm{sf}}{ }^{-}$ (Figure 10(b)). The equation of initial compressive elastic modulus $\left(E^{-}\right)$of SFCB could be presented as follows:

$$
E^{-}=\frac{E_{\mathrm{sf}}^{-} A_{\mathrm{sf}}}{\sqrt{\left(E_{\mathrm{s}} / E_{\mathrm{f}}^{-}\right)\left(A_{\mathrm{s}}\left(r_{\mathrm{sf}}^{-} /\left(1-r_{\mathrm{sf}}{ }^{-}\right)\right)\right)^{2}+2 A_{\mathrm{s}}\left(r_{\mathrm{sf}}^{-} /\left(1-r_{\mathrm{sf}}{ }^{-}\right)\right)+A_{\mathrm{s}}^{2}}} .
$$




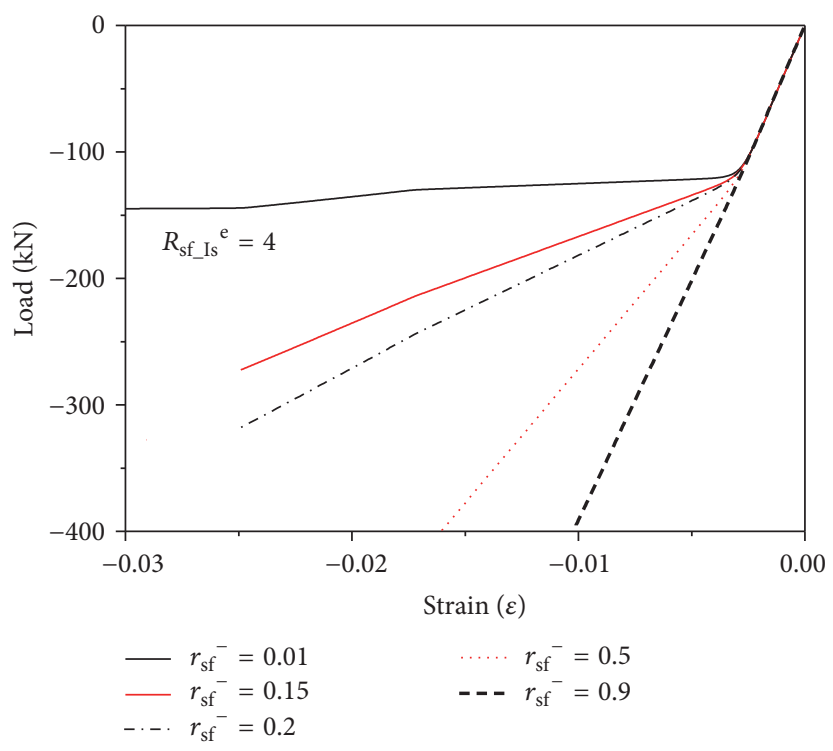

(a) Load-strain $\left(L_{\mathrm{u}} / d_{\text {sf_Is }}{ }^{\mathrm{e}}=4\right)$

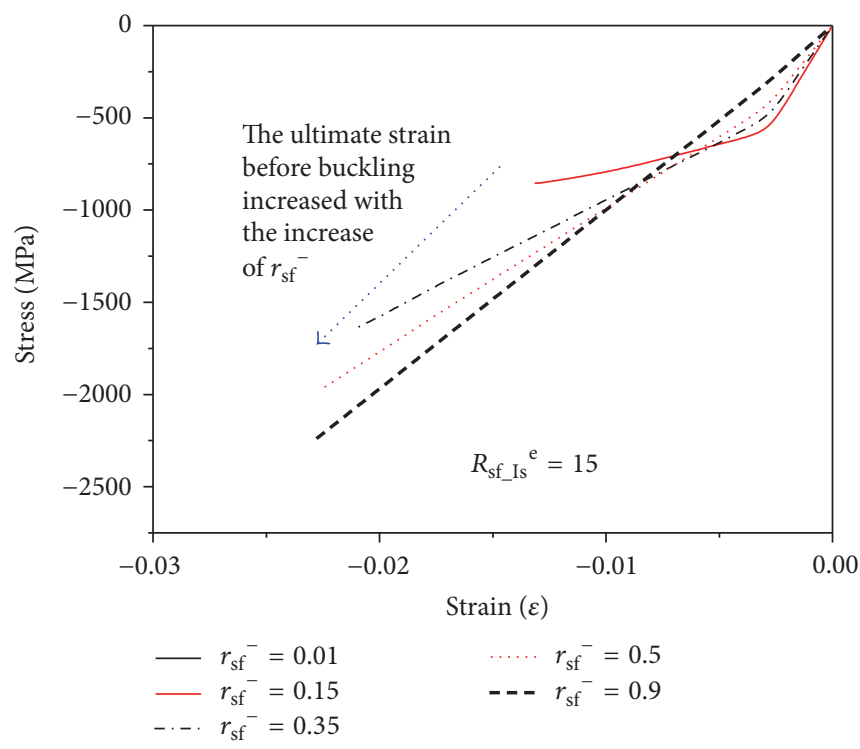

(c) Stress-strain $\left(L_{\mathrm{u}} / d_{\mathrm{sf} \_\mathrm{Is}}{ }^{\mathrm{e}}=15\right)$

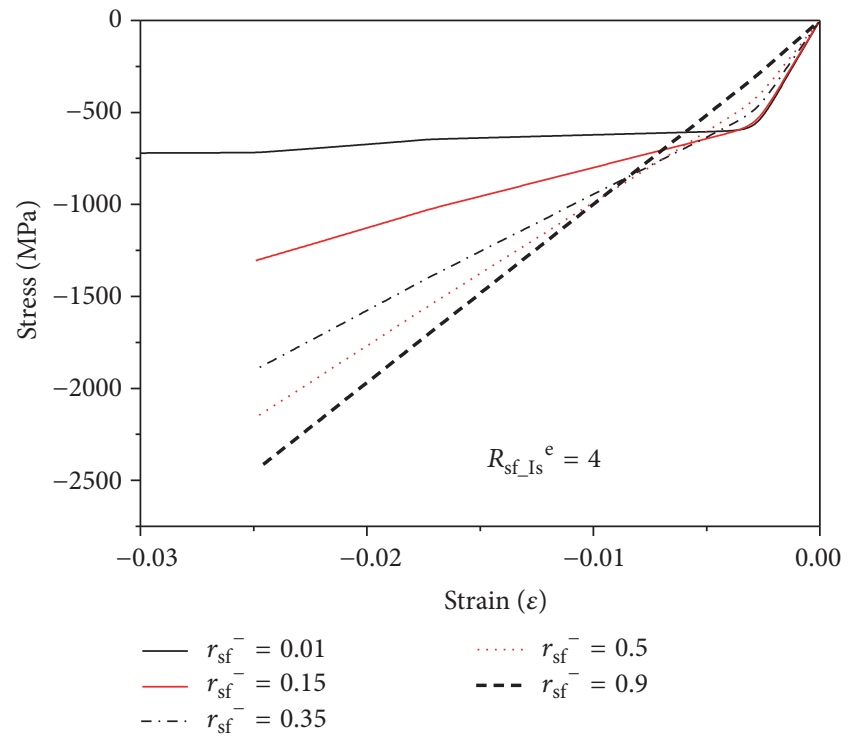

(b) Stress-strain $\left(L_{\mathrm{u}} / d_{\text {sf_Is }}{ }^{\mathrm{e}}=4\right)$

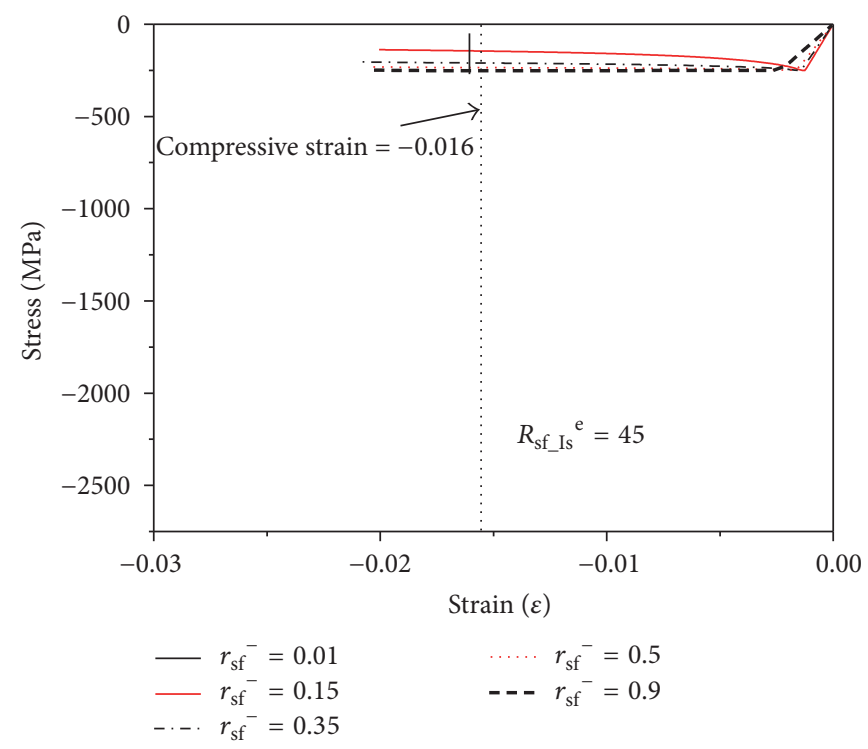

(d) Stress-strain $\left(L_{\mathrm{u}} / d_{\mathrm{sf} \_ \text {_s }}{ }^{\mathrm{e}}=45\right)$

FIgURE 10: The compressive behavior of SFCB.

When $r_{\mathrm{sf}}{ }^{-}$is relatively small, the stiffness degradation increases significantly with the increase of $L_{\mathrm{u}} / d_{\text {sf Is }}{ }^{\mathrm{e}}$ after the average stress reaches the peak stress. When the value of $L_{\mathrm{u}} / d_{\text {sf Is }}{ }^{\mathrm{e}}$ is between 4 and 15 , the yield occurred first, and then a stable postyield stiffness was obtained (Figure 10(b)), which is similar to the tension behavior. With an increase in $L_{\mathrm{u}} / d_{\text {sf_Is }}{ }^{\mathrm{e}}$, the SFCB with a lower $r_{\text {sf }}$ value buckled earlier. In contrast, the SFCB with a higher $r_{\text {sf }}{ }^{-}$shows a better compression postyield stiffness. After the compressive yield of SFCB occurred, the ultimate stable strain increased with the increase of $r_{\mathrm{sf}}{ }^{-}$(Figure 10(c)). For example, when the values of $L_{\mathrm{u}} / d_{\mathrm{sf} \text { Is }}{ }^{\mathrm{e}}$ for SFCB were 15,20 , and 25 , the corresponding $r_{\mathrm{sf}}{ }^{-}$ to maintain a stable compressive postyield stiffness were 0.15 , 0.35 , and 0.50 , respectively. When the $L_{\mathrm{u}} / d_{\mathrm{sf} \text { Is }}{ }^{\mathrm{e}}$ is between
30 and 45, elastic buckling occurred in all of the SFCBs. However, the slope of the compressive postbuckling curves varies from negative stiffness to zero stiffness as the $r_{\mathrm{sf}}{ }^{-}$ value increases (Figure 10(d)). For example, the postbuckling stress of an ordinary steel bar decreased dramatically with the development of compressive loading, while for SFCB, when $r_{\mathrm{sf}}{ }^{-}=0.35$, the postbuckling stress-strain curve could maintain a horizontal line, which indicates a stable postbuckling capacity can be realized. This phenomenon is similar to that of the elastic FRP bars after elastic buckling.

The relationship between the compressive postyield stiffness ratio and tensile postyield stiffness ratio is illustrated in Figure 11, where the compression postyield stiffness ratio is fitted by using compressive strain values between -0.0054 


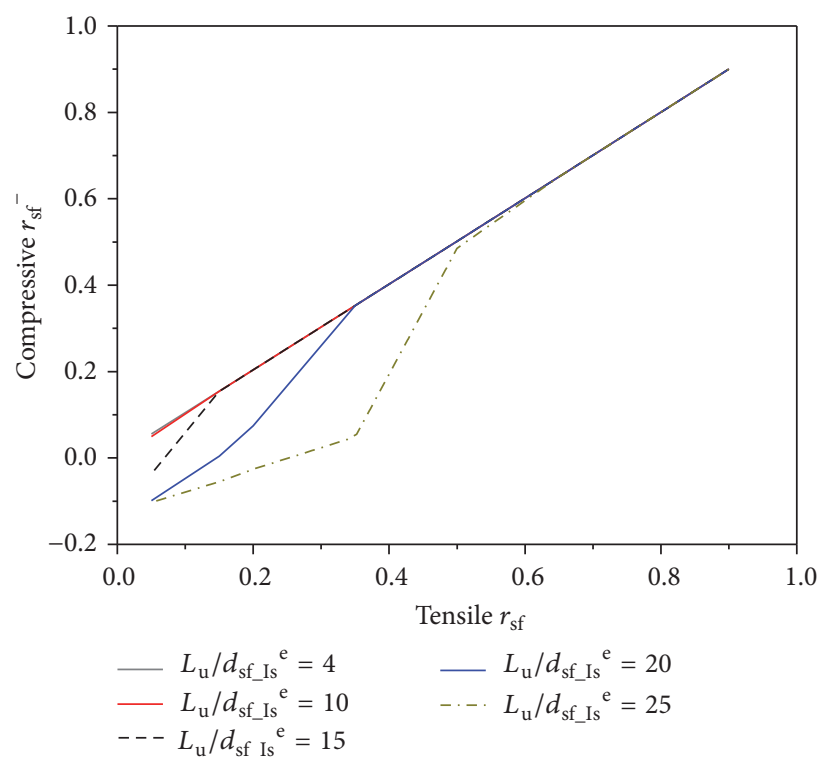

FIgURE 11: The relationship between the values of tensile $r_{\mathrm{sf}}$ and compressive $r_{\text {sf }}$.

and -0.0064 . It can be found that, with an increase in $L_{\mathrm{u}} / d_{\text {sf_Is }}{ }^{\mathrm{e}}$, the demands on $r_{\mathrm{sf}}{ }^{-}$to maintain a stable compressive postyield stiffness increase.

With an increase of $r_{\text {sf }}$, the buckling loads of SFCBs with the same initial stiffness gradually increase, while the equivalent stresses remained constant. The stress in the descending part of elastic buckling also increases with an increase of $r_{\text {sf }}{ }^{-}$, until the buckling stress is reached. By comparing the stress values of the two sets of elastic buckling specimens $\left(L_{\mathrm{u}} / d_{\text {sf Is }}\right.$ e equal to 45 and 50$)$, the average compression stress was a function of $r_{\mathrm{sf}}{ }^{-}$(when the compressive strain was $-0.016)$ and basically independent of $L_{\mathrm{u}} / d_{\mathrm{sf} \text { Is }}{ }^{\mathrm{e}}$. When $r_{\mathrm{sf}}{ }^{-}$ was between 0 and 0.8 , (10) can be obtained with a coefficient of determination $R^{2}$ equal to 0.998 (Figure 12). After the value of $r_{\text {sf }}{ }^{-}$reached 0.8 for the SFCB, the compressive stress was approximately equal to the peak buckling stress

$$
\begin{aligned}
& \frac{f_{\text {cr_- } 0.016}{ }^{\mathrm{e}}}{f_{\text {cr_sf }}{ }^{\mathrm{e}}}=-1.437\left({r_{\text {sf }}}^{-}\right)^{2}+2.004\left({r_{\text {sf }}}^{-}\right)+0.3024 \\
& r_{\mathrm{sf}} \leq 0.8
\end{aligned}
$$

4.4. Compression Failure Modes of SFCB. Based on the above parametric analysis, it can be found that there are three compression failure modes of SFCB (Figure 13): (a) elastic buckling before the yield of the inner steel bar; (b) buckling failure after the yield of the inner steel of the SFCB; and (c) the SFCB reaching its ultimate strength. When the failure mode is elastic buckling, the postpeak stress carrying capacity increases with the increase in $r_{\text {sf }}{ }^{-}$, until it reaches the peak buckling stress.

The determination methods of different failure modes are as follows:

(1) When $P_{\text {cr }}<P_{\text {sfy }}$, elastic buckling occurred, the peak buckling stress can be calculated using (8), and the postpeak stress is expressed by (10).

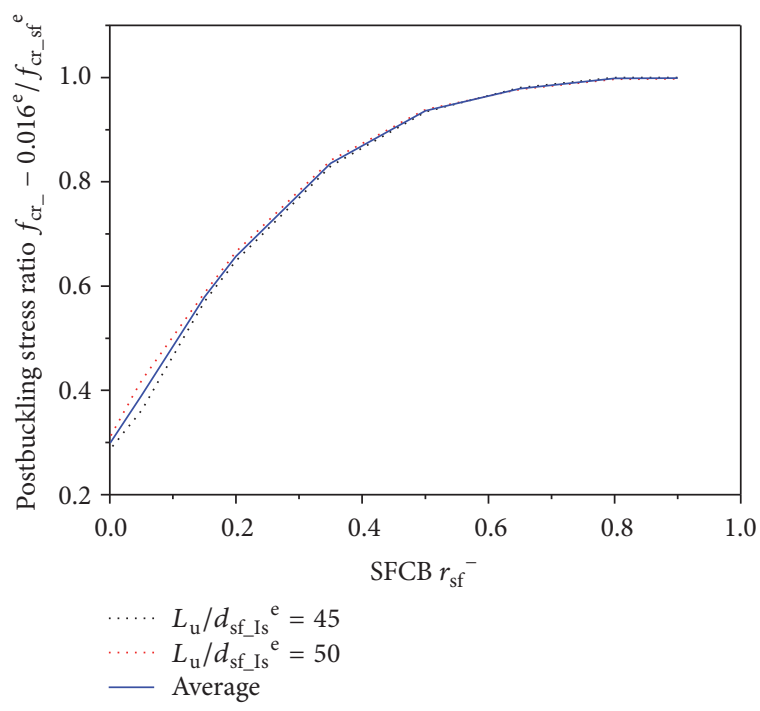

FIGURE 12: The postpeak stress of SFCB with elastic buckling.

(2) When the critical load is between the yield load of the SFCB $\left(P_{\text {sfy }} \leq P_{\text {cr }}\right)$ and the ultimate load, the elastic buckling equation is no longer applicable. In this case the load increase after yield is defined as $P_{\text {cr_sf_part2 }}=$ $P_{\text {cr_sf_f }}-P_{\text {sfy_f }}$. This is a load equal to the critical buckling load of the FRP minus the yield load carried by the FRP $\left(P_{\text {cr_sf_part2 }}+P_{\text {sfy }}<P_{\text {sfu }}\right)$. The failure mode is SFCB buckling after the yield of the inner steel bar.

(3) When the critical load reaches the ultimate compressive strength of the SFCB, no buckling occurred.

\section{Conclusions}

Based on the factory-produced SFCB, the mechanical properties of SFCB under tensile, repeated tensile, and compressive loading are analyzed, and the following conclusions can be drawn:

(1) The interface of an SFCB manufactured by round rebar and FRP cannot be guaranteed, and roving should be placed between the inner ribbed steel bar and outer longitudinal fibers to ensure the interface performance.

(2) The mechanical behavior of SFCB under repeated tensile loading can be well simulated in OpenSees. Similar to a pure FRP bar, the ultimate strength of SFCB slightly decreases with an increase in FRP content. Due to the elastic property of FRP, the residual strain of SFCB (S10-B20) can be reduced by more than $10 \%$ after the unloading strain reached $13500 \mu \varepsilon$.

(3) The elastic buckling stress of SFCB with different postyield stiffness ratios can be unified by the corresponding equivalent length-to-diameter ratio of the SFCB based on the equivalent flexural rigidity. When the buckling of SFCB occurred after yield of the inner steel bar, the postyield buckling load of SFCB 


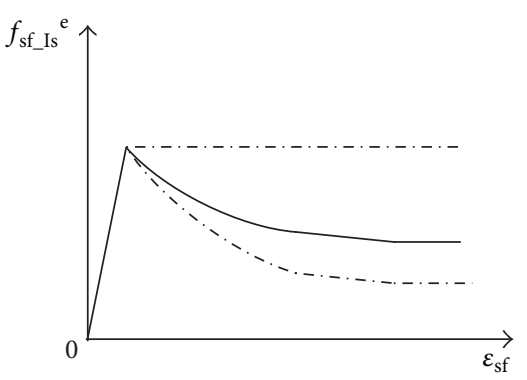

(a) Elastic buckling before yield

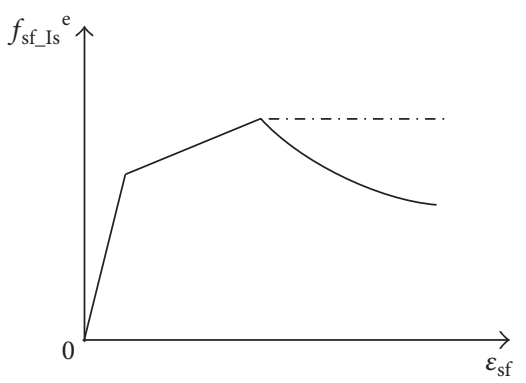

(b) Buckling failure after yield

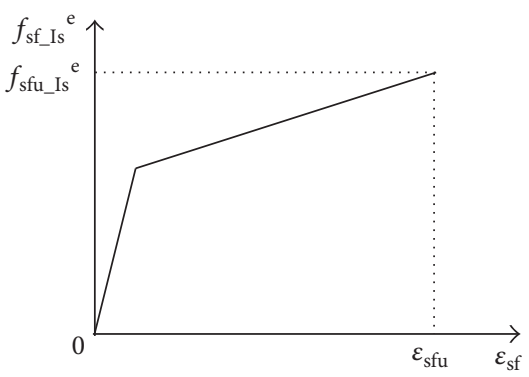

(c) Strength failure

FIGURE 13: Schematic compression failure modes of SFCB.

increases with the increase in the postyield stiffness, and the contribution of the FRP bar to the buckling load should be considered. An empirical equation for the postbuckling stress considering the effect of $r_{\mathrm{sf}}{ }^{-}$ was proposed.

\section{Competing Interests}

The authors declare that there is no conflict of interests regarding the publication of this paper.

\section{Acknowledgments}

The authors acknowledge the financial support from the National Key Technology Support Program of China (2014BAK11B04), the National Natural Science Foundation of China (nos. 51408126, 51528802), the Natural Science Foundation of Jiangsu Province, China (no. BK20140631), and the project funding from the Priority Academic Program Development of Jiangsu Higher Education Institutions (CE01-2-3).

\section{References}

[1] L. Lam and J. G. Teng, "Strength models for fiber-reinforced plastic-confined concrete," Journal of Structural Engineering, vol. 128, no. 5, pp. 612-623, 2002.

[2] J. Deng, T. Liu, W. Xie, and W. Lu, "Study on repaired earthquake-damaged bridge piers under seismic load," Advances in Materials Science and Engineering, vol. 2015, Article ID 295392, 10 pages, 2015.

[3] "Prestressing concrete structures with FRP tendons," ACI 440.4R-04, 2004.

[4] D. Lau and H. J. Pam, "Experimental study of hybrid FRP reinforced concrete beams," Engineering Structures, vol. 32, no. 12, pp. 3857-3865, 2010.

[5] A. Nanni, M. J. Henneke, and T. Okamoto, "Tensile properties of hybrid rods for concrete reinforcement," Construction and Building Materials, vol. 8, no. 1, pp. 27-34, 1994.

[6] B. Saikia, J. Thomas, A. Ramaswamy, and K. S. N. Rao, "Performance of hybrid rebars as longitudinal reinforcement in normal strength concrete," Materials and Structures, vol. 38, no. 10, pp. 857-864, 2005.

[7] G. Wu, Z. S. Wu, Y. B. Luo, and H. C. Wei, "A new reinforcement material of steel fiber composite bar (SFCB) and its mechanics properties," in Proceedings of the 9th International Symposium on "Fiber Reinforced Polymer (FRP) Reinforcement for Concrete Structures" (FRPRCS-9), University of Adelaide, Adelaide, Australia, July 2009.

[8] J. Sim, C. Park, and D. Y. Moon, "Characteristics of basalt fiber as a strengthening material for concrete structures," Composites Part B: Engineering, vol. 36, no. 6-7, pp. 504-512, 2005.

[9] X. Wang, Z. Wu, G. Wu, H. Zhu, and F. Zen, "Enhancement of basalt FRP by hybridization for long-span cable-stayed bridge," Composites Part B: Engineering, vol. 44, no. 1, pp. 184-192, 2013.

[10] X. Zhao, X. Wang, Z. Wu, and Z. Zhu, "Fatigue behavior and failure mechanism of basalt FRP composites under long-term cyclic loads," International Journal of Fatigue, vol. 88, pp. 58-67, 2016.

[11] G. Wu, Z.-S. Wu, Y.-B. Luo, Z.-Y. Sun, and X.-Q. Hu, "Mechanical properties of steel-frp composite bar under uniaxial and cyclic tensile loads," Journal of Materials in Civil Engineering, vol. 22, no. 10, pp. 1056-1066, 2010.

[12] Z. Y. Sun, Y. Yang, W. H. Qin, S. T. Ren, and G. Wu, "Experimental study on flexural behavior of concrete beams reinforced by steel-fiber reinforced polymer composite bars," Journal of Reinforced Plastics and Composites, vol. 31, no. 24, pp. 1737-1745, 2012.

[13] Z. Y. Sun, G. Wu, Z. S. Wu, and Y. B. Luo, "Flexural strengthening of concrete beams with near-surface mounted steelfiber-reinforced polymer composite bars," Journal of Reinforced Plastics and Composites, vol. 30, no. 18, pp. 1529-1537, 2011.

[14] A. I. Ibrahim, G. Wu, and Z. Sun, "Experimental study of cyclic behavior of concrete bridge columns reinforced by steel basaltfiber composite bars and hybrid stirrups," Journal of Composites for Construction, 2016.

[15] Z.-Y. Sun, G. Wu, Z.-S. Wu, and M. Zhang, "Seismic behavior of concrete columns reinforced by steel-FRP composite bars," Journal of Composites for Construction, ASCE, vol. 15, no. 5, pp. 696-706, 2011.

[16] G. R. Pandey, H. Mutsuyoshi, and T. Maki, "Seismic performance of bond controlled RC columns," Engineering Structures, vol. 30, no. 9, pp. 2538-2547, 2008.

[17] S. Mazzoni, F. McKenne, M. H. Scott, and G. L. Fenves, Open System for Earthquake Engineering Simulation User Manual Version 2.0, Pacific Earthquake Engineering Center, University of California, Berkeley, Calif, USA, 2009, http://opensees .berkeley.edu/OpenSees/manuals/usermanual/index.html.

[18] M. M. Kashani, A. J. Crewe, and N. A. Alexander, "Nonlinear stress-strain behaviour of corrosion-damaged reinforcing bars including inelastic buckling," Engineering Structures, vol. 48, pp. 417-429, 2013. 
[19] S. Bae, A. M. Mieses, and O. Bayrak, "Inelastic buckling of reinforcing bars," Journal of Structural Engineering, vol. 131, no. 2, pp. 314-321, 2005.

[20] J. B. Mander, F. D. Panthaki, and A. Kasalanati, "Low-cycle fatigue behavior of reinforcing steel," Journal of Materials in Civil Engineering, vol. 6, no. 4, pp. 453-468, 1994.

[21] R. Hawileh, A. Rahman, and H. Tabatabai, "Evaluation of the low-cycle fatigue life in ASTM A706 and A615 grade 60 steel reinforcing bars," Journal of Materials in Civil Engineering, vol. 22, no. 1, pp. 65-76, 2010.

[22] J. Zheng, Experimental studies on cyclic behavior of reinforcing bars including buckling [M.S. thesis], Chongqing University, 2012 (Chinese).

[23] "Guide for the design and construction of concrete reinforced with FRP bars," ACI 440.1R-06, 2006.

[24] W. P. Wu, Thermomechanical properties of Fiber Reinforced Plastic (FRP) bars [Ph.D. dissertation], West Virginia University, Morgantown, WVa, USA, 1992.

[25] S. Zhou, Study on the basic mechanical performance of concrete members with BFRP bars [M.S. thesis], Southeast University, 2012 (Chinese). 

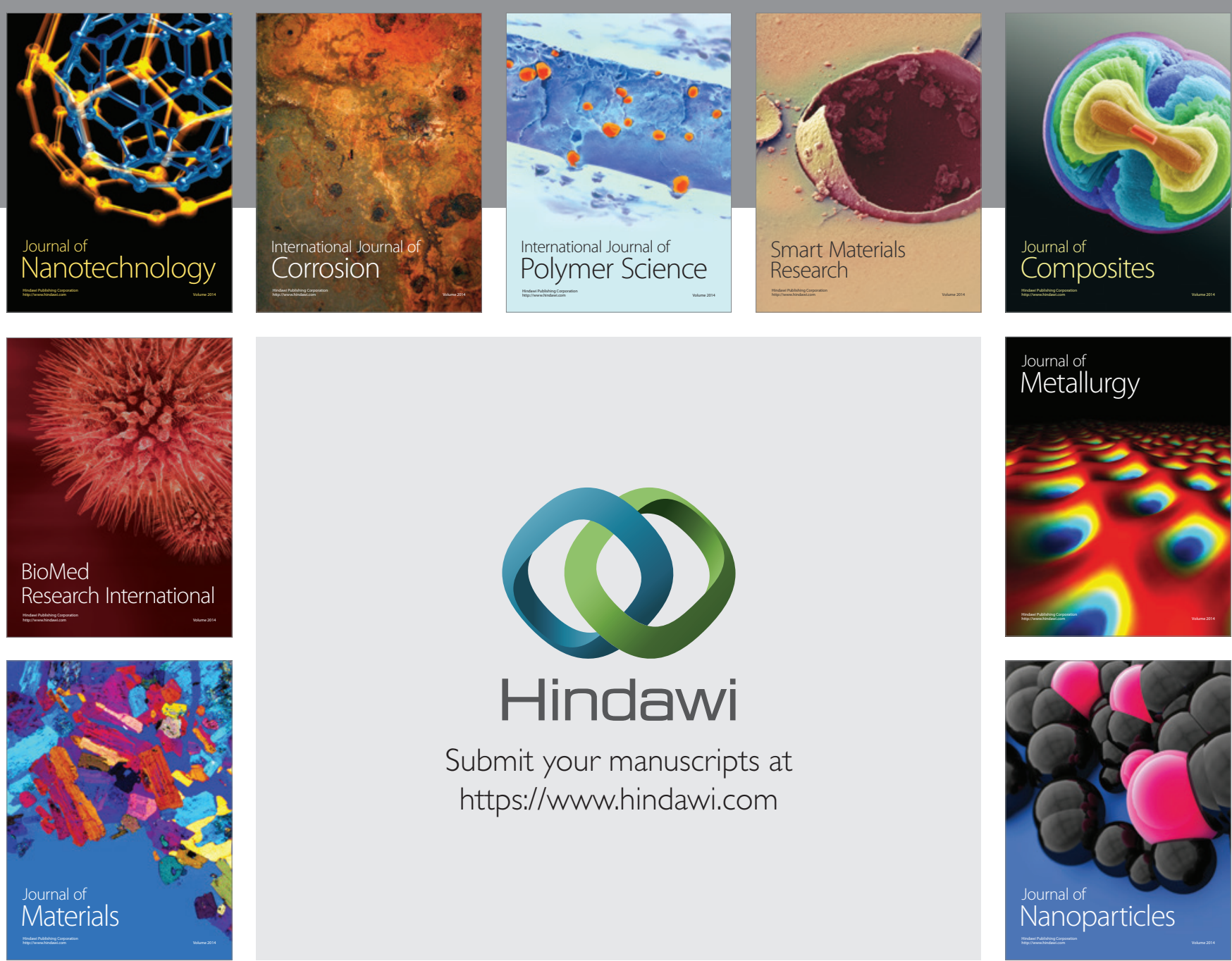

\section{Hindawi}

Submit your manuscripts at

https://www.hindawi.com

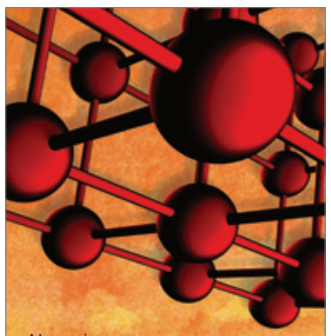

Materials Science and Engineering
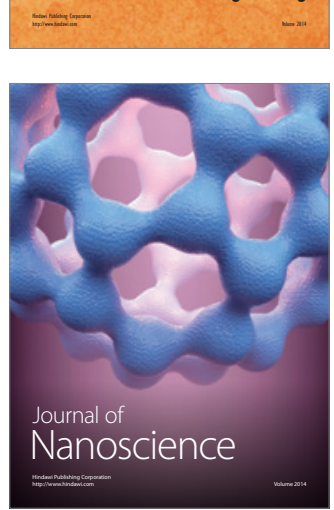
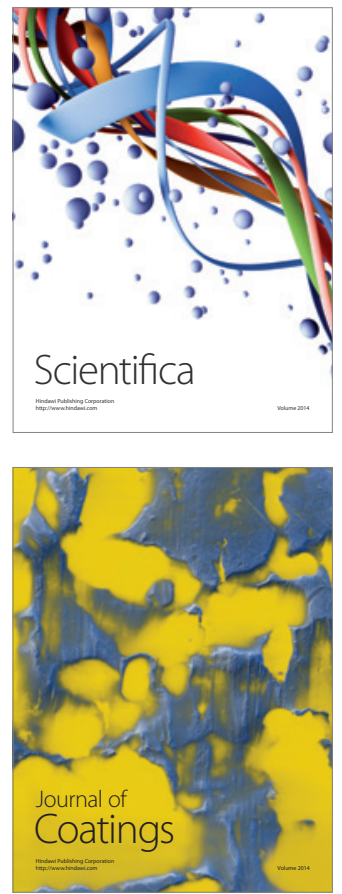
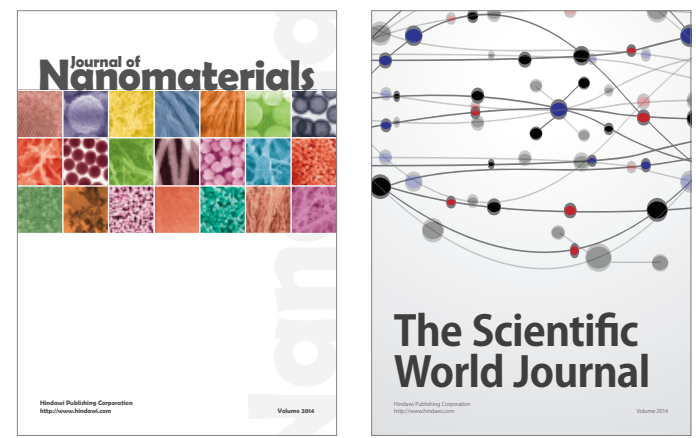

The Scientific World Journal
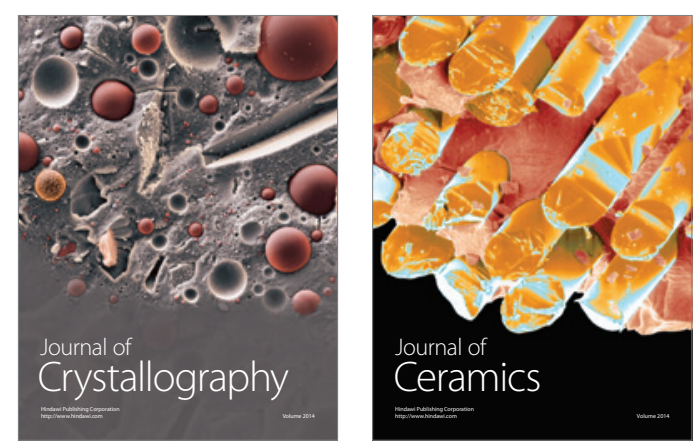
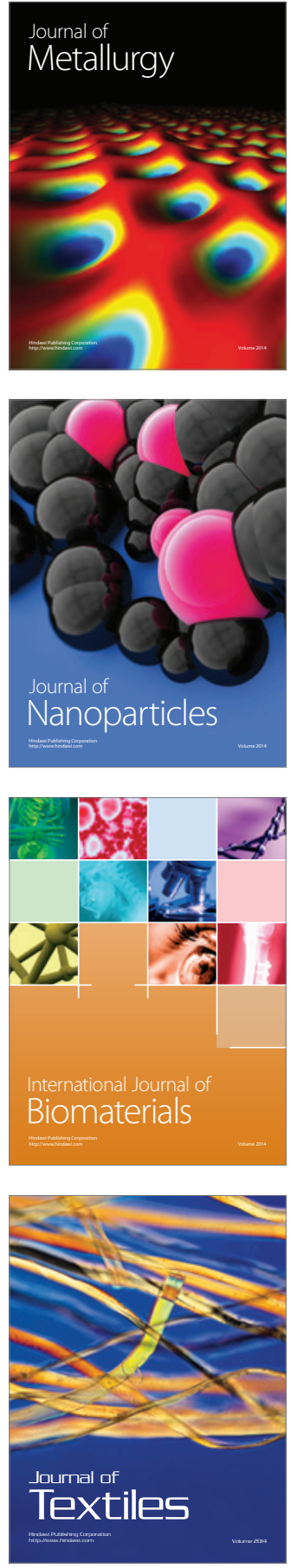